\title{
Transforaminal endoscopic discectomy to relieve sciatica and delay fusion in a 31-year-old man with pars defects and low-grade spondylolisthesis
}

\author{
Karthik Madhavan, MD, ${ }^{2}$ Lee Onn Chieng, BS, ${ }^{2}$ Christoph P. Hofstetter, MD, PhD, ${ }^{1}$ and \\ Michael Y. Wang, MD²
}

'Department of Neurological Surgery, University of Washington, Seattle, Washington; and 2Department of Neurological Surgery and the Miami Project to Cure Paralysis, University of Miami Miller School of Medicine, Miami, Florida

\begin{abstract}
Isthmic spondylolisthesis due to pars defects resulting from trauma or spondylolysis is not uncommon. Symptomatic patients with such pars defects are traditionally treated with a variety of fusion surgeries. The authors present a unique case in which such a patient was successfully treated with endoscopic discectomy without iatrogenic destabilization.
\end{abstract}

A 31-year-old man presented with a history of left radicular leg pain along the distribution of the sciatic nerve. He had a disc herniation at L5/S1 and bilateral pars defects with a Grade I spondylolisthesis. Dynamic radiographic studies did not show significant movement of L-5 over S-1. The patient did not desire to have a fusion. After induction of local anesthesia, the patient underwent an awake transforaminal endoscopic discectomy via the extraforaminal approach, with decompression of the L-5 and S-1 nerve roots. His preoperative pain resolved immediately, and he was discharged home the same day. His preoperative Oswestry Disability Index score was 74, and postoperatively it was noted to be 8 . At 2-year follow-up he continued to be symptom free, and no radiographic progression of the listhesis was noted.

In this case preservation of stabilizing structures, including the supraspinous and interspinous ligaments and the facet capsule, may have reduced the likelihood of iatrogenic instability while at the same time achieving symptom control. This may be a reasonable option for select patient symptoms confined to lumbosacral radiculopathy.

http://thejns.org/doi/abs/10.3171/2015.11.FOCUS15512

KEY WORDS endoscopic spine surgery; pars defect; transforaminal; spondylolisthesis

$\mathrm{T}$ HE most common forms of lumbar spondylolisthesis are 1) degenerative, from the facet and disc degeneration seen in the elderly; ${ }^{16}$ and 2) isthmic, from a pars fracture beginning at a younger age.,8 Traditionally, spondylolisthesis due to pars defects is thought to be associated with mechanical instability and is therefore typically treated with arthrodesis surgery. ${ }^{18,20,21}$ Surgery for decompression, fusion, and instrumentation can treat not only symptoms of neural compression but also axial back pain. This is accomplished through indirect or direct neural decompression, removal of pathological motion, and realignment of the vertebrae.

However, fusion surgery, particularly in younger patients, carries clear sequelae that may be undesirable. These include a more morbidity-producing operative intervention, loss of segmental motion, increased stress on adjacent levels, fusion into suboptimal alignment, ${ }^{14,15,26}$ and all of the typical complications associated with fusion and instrumentation, such as pseudarthrosis and hardware problems. . $^{1,3,28}$

In some patients only symptoms of neural compression will be seen. For these patients decompression without fusion remains a possibility. However, traditional bilateral open laminectomy probably further iatrogenically destabilizes the treated functional segmental unit, potentially leading to further slip progression. Thus, most surgeons will favor the fusion operation to prevent these effects.

Transforaminal endoscopic discectomy is a minimally invasive procedure that can focally decompress unilateral nerve root compression through disc removal or foraminal enlargement. ${ }^{2}$ In this report we present a case in which a patient who had a disc herniation at Grade I spondylolisthesis attained relief of his radicular symptoms without a fusion, by using transforaminal endoscopic discectomy. 


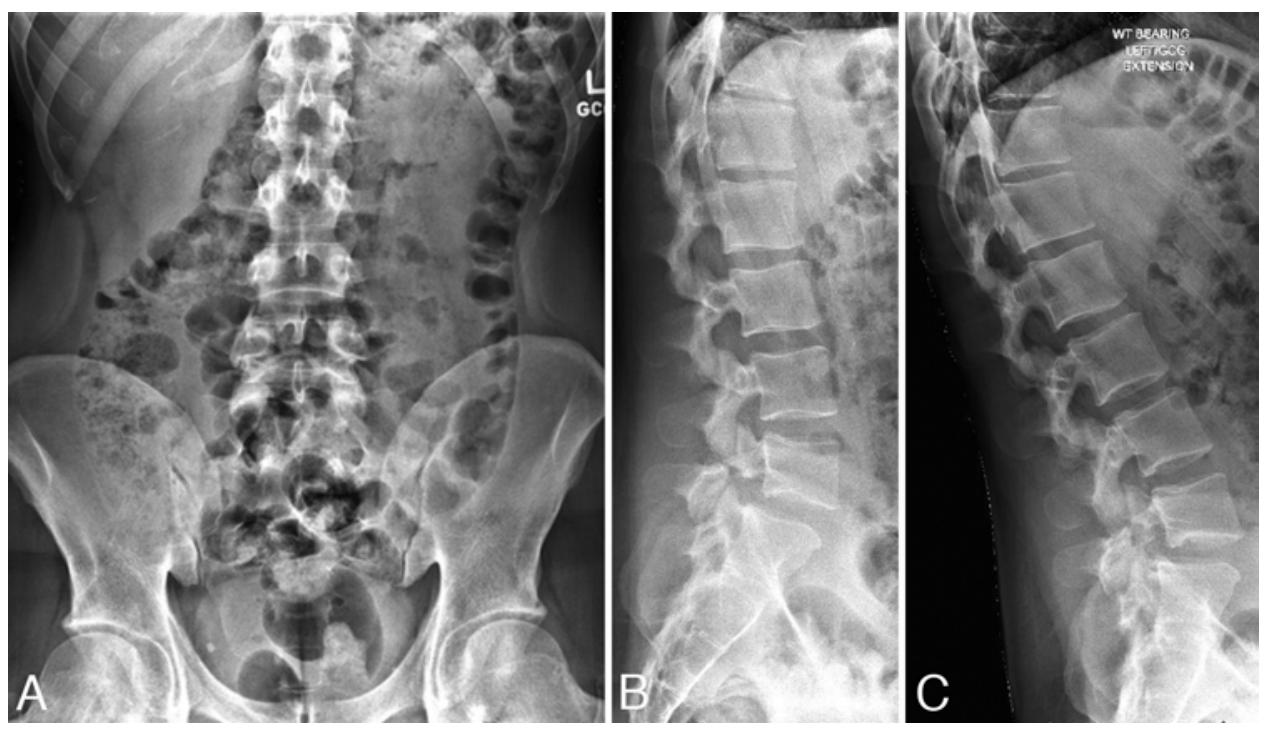

FIG. 1. A: Preoperative anteroposterior (AP) radiograph of the lumbar spine (weight bearing) shows no signs of coronal deformity. B and C: Preoperative flexion and extension films show Grade I isthmic spondylolisthesis with no significant movements on dynamic views. The pars defect is well visualized on both radiographs.

This approach is truly minimally invasive and minimizes disruption of the musculoskeletal structures, and thus is less likely to result in iatrogenic slip progression.

\section{Case Report}

History and Examination

The patient was a 31-year-old man who presented to clinic with a history of leg pain and mild back pain for more than 1 year. He was an avid basketball player, but his condition progressively worsened, to the point that he was unable to walk more than 10 feet before he had to rest. His leg pain was worse than the back pain by a 9:1 ratio. $\mathrm{He}$ had numbness over the gluteal area that extended down the back of his thigh to the knee. Preoperative visual ana$\log$ scale (VAS) scores were 8-9 of 10. On examination the patient had some numbness in the foot, but no motor deficit was noted.

\section{Neuroimaging Findings}

Imaging revealed bilateral pars defects with Grade I spondylolisthesis at the L5-S1 level, with a disc herniation on the left compressing the S-1 nerve root. Dynamic flexion-extension radiographs of the lumbar spine showed minimal movement of L-5 over S-1 (Figs. 1-3). Extensive conservative management with NSAIDs, epidural injections, and physical therapy had failed in this patient over a period of 8 months. After an extensive discussion it was clear that because of his young age he would like to avoid a fusion surgery if possible.

\section{Operation}

The patient underwent a left-sided L5/S1 transforaminal endoscopic discectomy with intraoperative discography. The patient was positioned prone under monitored anesthesia care. Using fluoroscopy, the L5-S1 disc space was accessed through Kambin's triangle using successive dilators and reamers through a 7-mm left flank incision. The herniated disc was removed and a foraminal enlargement was achieved with bone shavers, curettes, and endoscopic osteotomes.

\section{Postoperative Course}

The patient did well postoperatively and was discharged home 2 hours after surgery on the same day. His preoperative Oswestry Disability Index (ODI) score was 74 , and this was reduced to 8 . He continued to do well with regular follow-up. At 2 years after surgery he continued to be free from radicular and back pain, with a sustained ODI score of 8 . His postoperative VAS scores were 1-2 of 10. His dynamic radiographs showed no increase in motion or slippage (Fig. 4).

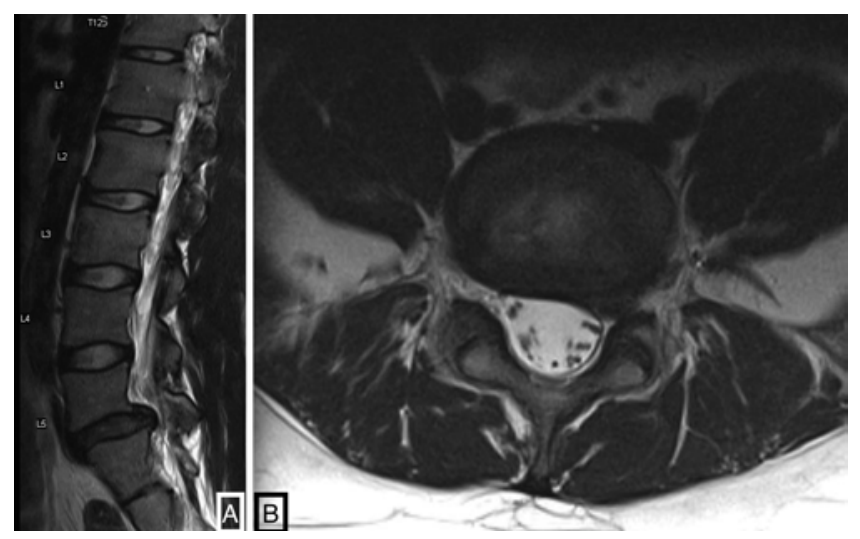

FIG. 2. Sagittal (A) and axial (B) T2-weighted MRI sequences of the lumbar spine revealing the disc herniation in both views, showing the compression of the S-1 nerve root. Of note, the disc height is well preserved, although lack of water content is appreciated when compared with the discs above. 


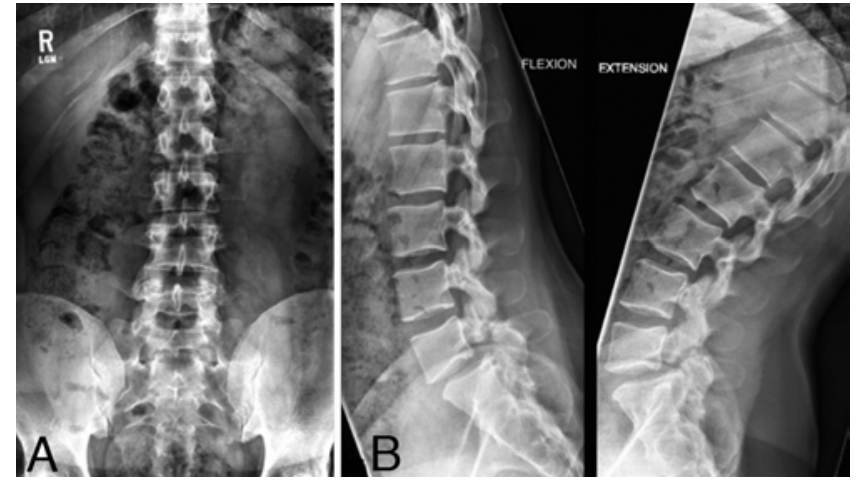

FIG. 3. A: Postoperative AP image shows no signs of new coronal deformity or formation of fractional curve. B: Postoperative dynamic flexion-extension radiographs show spondylolisthesis but no significant movement or worsening of the L5-S1.

\section{Discussion}

The vertebral column is maintained in a stable position by bony joints supported by muscles and ligaments. The stress and strain relationships with spinal ligaments are nonlinear and biphasic. There is a very low modulus of elasticity in the beginning and a very high modulus just before disintegrating. This implies that even with high strains there is less stress in the ligaments. This provides an optimum range of motion and absorbs a large amount of stress energy. ${ }^{22,29}$ Panjabi et al. showed that the maximum strain during flexion is on the supraspinous and interspinous ligament, with an intact pars in up to $18 \% .^{23}$ Also, ligamentum flavum provides additional support and biomechanical studies have shown that the failure strains have been $22 \%-80 \% .{ }^{22,24}$ In a patient with spondylolisthesis from pars defects this stress on supraspinous and interspinous ligaments, ligamentum flavum, and anterior and posterior longitudinal ligaments is significantly increased, so that every structure is crucial for better load sharing.?

With this understanding, we offered our 31-year-old patient the options of anterior lumbar interbody fusion, posterior instrumented fusion, microdiscectomy, and endoscopic transforaminal microdiscectomy. The patient was young and planned to have children in the future, which made the option of anterior lumbar interbody fusion less desirable because it can be associated with retrograde ejaculation. ${ }^{19}$ In addition, segmental fusion in a young patient might accelerate the need for possible additional fusions in the future from adjacent-level disease. ${ }^{9,12}$ Posterior interlaminar microdiscectomy would provide excellent symptomatic relief of radicular pain, but this comes at the cost of removal of the ligamentum flavum, medial facetectomy, and dissection of the paraspinal muscle, leading to worsening of the listhesis..$^{11,27}$

The long-term outcome in bilateral pars defects in athletes and young adults is often self-limited, with good healing and pain reduction in up to $80 \%$ of patients. ${ }^{5} \mathrm{How}-$ ever, some patients will remain symptomatic and require surgical intervention. Several treatment strategies can be used, ${ }^{10,17,25}$ and fusion surgery remains the standard choice. Although the results tend to be good, this outcome is not universal. ${ }^{25}$ In a subset of patients who had associated lowgrade spondylolisthesis, minimal or no disc herniation, and age less than 20 years, direct pars repair might be favorable. Recently, minimally invasive surgery pars screw fixation techniques have been described by several groups of investigators. ${ }^{6,30,31}$ In their case series of 8 athletes, Gillis and colleagues ${ }^{13}$ demonstrated robust improvement of symptoms, which allowed a return to sport at their previous level in 6 of 8 patients. Not until 4 years later was lumbar fusion indicated in 1 patient.

In regard to our patient, because the symptoms clearly resulted from the significant disc herniation, we chose to undertake an incremental approach. It is most likely that this patient will ultimately require a fusion at the index site. However, given his unilateral radicular symptoms without back pain, his young age, the potential for an active lifestyle, and understanding of the treatment plan, we elected to perform the least morbidity-producing and least destabilizing operative intervention.

\section{Conclusions}

The preservation of critical structures and not the size of the incision defines the true essence of minimally invasive spine surgery. Microdiscectomy per se does not lead to instability of the spine but can contribute to worsening of existing spondylolisthesis. In this report we present a different option for treating a disc herniation in a patient with bilateral pars defect without fusion.
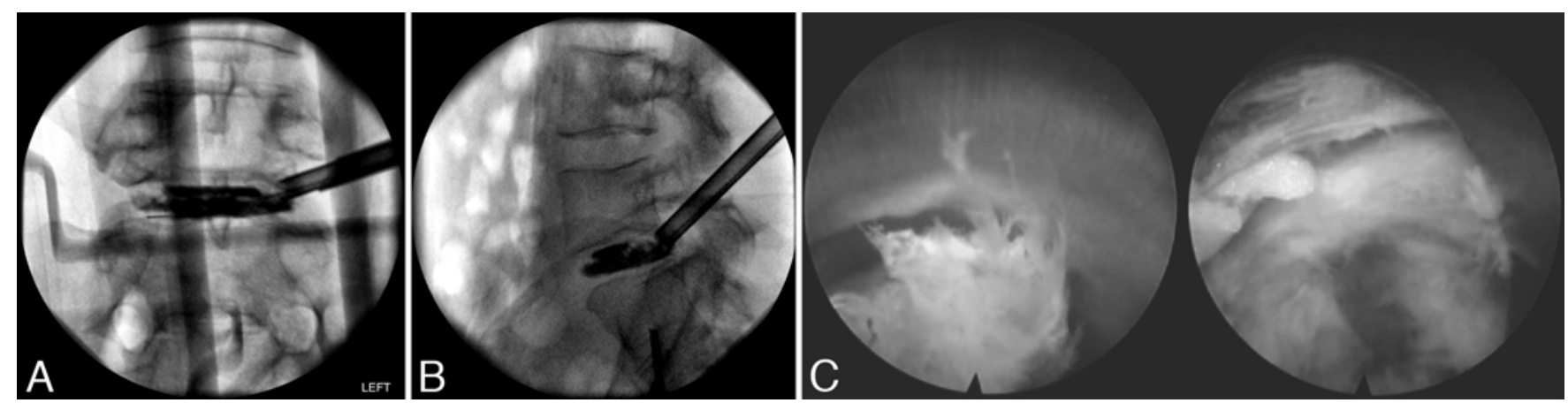

FIG. 4. Intraoperative image showing AP (A) and lateral $(B)$ views, where the position of the endoscope is evaluated with a balloon. Intraoperative images (C) taken with an endoscope after reaming of the anulus at the beginning of the procedure (left) and postdiscectomy (right). 


\section{References}

1. Ahmad FU, Madhavan K, Trombly R, Levi AD: Anterior thigh compartment syndrome and local myonecrosis after posterior spine surgery on a Jackson table. World Neurosurg 78:553.e5-553.e8, 2012

2. Ahn SS, Kim SH, Kim DW, Lee BH: Comparison of outcomes of percutaneous endoscopic lumbar discectomy and open lumbar microdiscectomy for young adults: a retrospective matched cohort study. World Neurosurg [epub ahead of print], 2015

3. Bae JS, Lee SH, Kim JS, Jung B, Choi G: Adjacent segment degeneration after lumbar interbody fusion with percutaneous pedicle screw fixation for adult low-grade isthmic spondylolisthesis: minimum 3 years of follow-up. Neurosurgery 67:1600-1608, 2010

4. Blanda J, Bethem D, Moats W, Lew M: Defects of pars interarticularis in athletes: a protocol for nonoperative treatment. J Spinal Disord 6:406-411, 1993

5. Bono CM: Low-back pain in athletes. J Bone Joint Surg Am 86-A:382-396, 2004

6. Brennan RP, Smucker PY, Horn EM: Minimally invasive image-guided direct repair of bilateral L-5 pars interarticularis defects. Neurosurg Focus 25(2):E13, 2008

7. Chen CS, Feng CK, Cheng CK, Tzeng MJ, Liu CL, Chen WJ: Biomechanical analysis of the disc adjacent to posterolateral fusion with laminectomy in lumbar spine. J Spinal Disord Tech 18:58-65, 2005

8. Congeni J, McCulloch J, Swanson K: Lumbar spondylolysis. A study of natural progression in athletes. Am J Sports Med 25:248-253, 1997

9. Etebar S, Cahill DW: Risk factors for adjacent-segment failure following lumbar fixation with rigid instrumentation for degenerative instability. J Neurosurg 90 (2 Suppl):163-169, 1999

10. Foreman P, Griessenauer CJ, Watanabe K, Conklin M, Shoja MM, Rozzelle CJ, et al: L5 spondylolysis/spondylolisthesis: a comprehensive review with an anatomic focus. Childs Nerv Syst 29:209-216, 2013

11. Gejo R, Matsui H, Kawaguchi Y, Ishihara H, Tsuji H: Serial changes in trunk muscle performance after posterior lumbar surgery. Spine (Phila Pa 1976) 24:1023-1028, 1999

12. Ghiselli G, Wang JC, Hsu WK, Dawson EG: L5-S1 segment survivorship and clinical outcome analysis after L4-L5 isolated fusion. Spine (Phila Pa 1976) 28:1275-1280, 2003

13. Gillis CC, Eichholz K, Thoman WJ, Fessler RG: A minimally invasive approach to defects of the pars interarticularis: Restoring function in competitive athletes. Clin Neurol Neurosurg 139:29-34, 2015

14. Girardo M, Bettini N, Dema E, Cervellati S: Uninstrumented posterolateral spinal arthrodesis: is it the gold standard technique for I degrees and II degrees grade spondylolisthesis in adolescence? Eur Spine J 18 (Suppl 1):126-132, 2009

15. Helenius I, Lamberg T, Osterman K, Schlenzka D, Yrjönen $\mathrm{T}$, Tervahartiala P, et al: Scoliosis research society outcome instrument in evaluation of long-term surgical results in spondylolysis and low-grade isthmic spondylolisthesis in young patients. Spine (Phila Pa 1976) 30:336-341, 2005

16. Jacobsen S, Sonne-Holm S, Rovsing H, Monrad H, Gebuhr P: Degenerative lumbar spondylolisthesis: an epidemiological perspective: the Copenhagen Osteoarthritis Study. Spine (Phila Pa 1976) 32:120-125, 2007

17. Jasper GP, Francisco GM, Aghion D, Telfeian AE: Technical considerations in transforaminal endoscopic discectomy with foraminoplasty for the treatment of spondylolisthesis: Case report. Clin Neurol Neurosurg 119:84-87, 2014

18. Jasper GP, Francisco GM, Telfeian AE: Transforaminal endoscopic discectomy with foraminoplasty for the treatment of spondylolisthesis. Pain Physician 17:E703-E708, 2014
19. Johnson RM, McGuire EJ: Urogenital complications of anterior approaches to the lumbar spine. Clin Orthop Relat Res (154):114-118, 1981

20. Kleinstueck FS, Fekete TF, Mannion AF, Grob D, Porchet F, Mutter U, et al: To fuse or not to fuse in lumbar degenerative spondylolisthesis: do baseline symptoms help provide the answer? Eur Spine J 21:268-275, 2012

21. Matsudaira K, Yamazaki T, Seichi A, Takeshita K, Hoshi K, Kishimoto J, et al: Spinal stenosis in grade I degenerative lumbar spondylolisthesis: a comparative study of outcomes following laminoplasty and laminectomy with instrumented spinal fusion. J Orthop Sci 10:270-276, 2005

22. Nachemson AL, Evans JH: Some mechanical properties of the third human lumbar interlaminar ligament (ligamentum flavum). J Biomech 1:211-220, 1968

23. Panjabi MM, Goel VK, Takata K: Physiologic strains in the lumbar spinal ligaments. An in vitro biomechanical study 1981 Volvo Award in Biomechanics. Spine (Phila Pa 1976) 7:192-203, 1982

24. Scapinelli R, Stecco C, Pozzuoli A, Porzionato A, Macchi V, De Caro R: The lumbar interspinous ligaments in humans: anatomical study and review of the literature. Cells Tissues Organs 183:1-11, 2006

25. Schnee CL, Freese A, Ansell LV: Outcome analysis for adults with spondylolisthesis treated with posterolateral fusion and transpedicular screw fixation. J Neurosurg 86:5663, 1997

26. Seitsalo S, Schlenzka D, Poussa M, Osterman K: Disc degeneration in young patients with isthmic spondylolisthesis treated operatively or conservatively: a long-term follow-up. Eur Spine J 6:393-397, 1997

27. Sihvonen T, Herno A, Paljärvi L, Airaksinen O, Partanen J, Tapaninaho A: Local denervation atrophy of paraspinal muscles in postoperative failed back syndrome. Spine (Phila Pa 1976) 18:575-581, 1993

28. Tsahtsarlis A, Efendy JL, Mannion RJ, Wood MJ: Complications from minimally invasive lumbar interbody fusion: experience from 100 patients. J Clin Neurosci 20:813-817, 2013

29. Waters RL, Morris JM: An in vitro study of normal and scoliotic interspinous ligaments. J Biomech 6:343-348, 1973

30. Widi GA, Williams SK, Levi AD: Minimally invasive direct repair of bilateral lumbar spine pars defects in athletes. Case Rep Med 2013:659078, 2013

31. Wilson L, Altaf F, Tyler P: Percutaneous pars interarticularis screw fixation: a technical note. Eur Spine J [epub ahead of print], 2015

\section{Disclosures}

Dr. Wang is a consultant for DePuy Spine, Aesculap Spine, joimax, and K2M. He is a patent holder with DePuy Spine. Dr. Hofstetter is a consultant for Johnson \& Johnson and for InVivo Therapeutics.

\section{Author Contributions}

Conception and design: Wang. Acquisition of data: Madhavan, Chieng. Analysis and interpretation of data: Madhavan, Chieng. Drafting the article: Madhavan. Critically revising the article: Madhavan, Hofstetter, Wang. Reviewed submitted version of manuscript: Madhavan. Administrative/technical/material support: Wang. Study supervision: Wang.

\section{Correspondence}

Karthik Madhavan, Lois Pope Life Center, 1095 N.W. 14th Terrace, Miami, FL 33126. email: drkarthik19@gmail.com. 